\title{
BMJ Open Factors influencing palliative care referral for hospitalised patients with heart failure: an exploratory, randomised, multi-institutional survey of hospitalists and cardiologists
}

Nauzley Christy Abedini (D) , ${ }^{1}$ Gaorui Guo, ${ }^{2}$ Scott L Hummel, ${ }^{3,4}$ David Bozaan, ${ }^{4,5}$ Michael Beasley, ${ }^{6}$ Jennifer Cowger, ${ }^{7}$ Vineet Chopra ${ }^{4,5}$

To cite: Abedini NC, Guo G, Hummel SL, et al. Factors influencing palliative care referral for hospitalised patients with heart failure: an exploratory, randomised, multi-institutional survey of hospitalists and cardiologists. BMJ Open 2020;10:e040857. doi:10.1136/ bmjopen-2020-040857

- Prepublication history and additional material for this paper is available online. To view these files, please visit the journal online (http://dx.doi.org/10. 1136/bmjopen-2020-040857)

Received 24 May 2020

Revised 05 October 2020

Accepted 25 November 2020

Check for updates

(C) Author(s) (or their employer(s)) 2020. Re-use permitted under CC BY-NC. No commercial re-use. See rights and permissions. Published by BMJ.

For numbered affiliations see end of article.

Correspondence to Dr Nauzley Christy Abedini; nauzley@gmail.com

\section{ABSTRACT}

Objective To identify factors influencing cardiologists' and hospitalists' decisions regarding palliative care referral among hospitalised patients with advanced heart failure.

Design An exploratory, randomised vignette-based survey.

Setting Cardiology and hospitalist divisions at three Michigan State institutions and the Society of Hospital Medicine's Michigan Chapter.

Participants 145 hospitalists and 64 cardiologists. Outcome measures Primary outcomes included participants' reports of their likelihood of referring a standardised patient with an acute heart failure exacerbation with multiple prior hospital admissions and acute renal failure to palliative care (scale of 0\%-100\%) after the initial stem and after being cued with three randomised vignette modifiers, including the presence versus the absence of continuity with an outpatient cardiologist; the presence versus the absence of documented advance care planning; and the patient voicing that he is accepting of his severe illness versus wanting everything done. Adjusted generalised linear models and predictive margins were used to evaluate the impact of each randomised modifier on referral decisions. An interaction term evaluated the effect of provider specialty on outcomes. Secondary outcomes included participants' reports of their general practices around palliative care delivery to hospitalised patients with heart failure.

Results Response rate was $31.3 \%$. Predictive margins from generalised linear models demonstrated a statistically significantly higher likelihood of referral to inpatient palliative care if the patient lacked an outpatient cardiologist (mean difference: $6.3 \%(95 \% \mathrm{Cl} 1.8 \%$ to $10.8 \%)$ ); had prior advance care planning documentation (mean difference: $9.7 \%$ (95\% Cl $4.4 \%$ to $15.0 \%)$ ); and was accepting of illness severity (mean difference: $29.6 \%(95 \% \mathrm{Cl} 24.8 \%$ to $34.4 \%)$ ). No interaction effect was noted based on provider specialty. Most hospitalists and cardiologists were unaware of palliative care guidelines for patients with heart failure $(74.3 \%$ vs $70.3 \%, p=0.71$ ).

\section{Strengths and limitations of the study}

- First such study to compare and contrast factors influencing hospitalist and cardiologist decisionmaking in palliative care referral for hospitalised patients with heart failure.

- Randomised vignette-based format provides helpful insights into provider decision-making.

- Low response rate, and most respondents came from academic settings which may limit generalisability.

- Lack of access to specialty palliative care is an important barrier to timely referral for patients with heart failure not addressed by our study.

Conclusions A number of patient and provider factors influence palliative care referral decisions in hospitalised patients with advanced heart failure.

\section{INTRODUCTION}

Advanced heart failure (HF) occurs when patients with HF experience persistent symptoms that interfere with daily living despite maximum medical therapy. Specialty palliative care (PC) can improve symptom burden and quality of life for patients with advanced HF when delivered early in the disease course and regardless of prognosis. ${ }^{12}$ However, the American College of Cardiology/American Heart Association guidelines only recommend PC for patients with end-stage (Stage D) $\mathrm{HF}^{3}{ }^{4}$ Over half of all patients with advanced HF die within a year of diagnosis, ${ }^{5}$ and 4 in every 5 such patients are hospitalised in the last 6 months of life. ${ }^{6}$ Less than $10 \%$ of patients with advanced $\mathrm{HF}$ are seen by PC within a year of a hospital admission. ${ }^{5}$ Thus, hospitalisations can serve as important intervention points at which to refer patients to $\mathrm{PC}$. 
The onus of identifying hospitalised patients with HF who may benefit from PC frequently falls on hospitalists who commonly care for these patients, rather than cardiologists. ${ }^{78}$ Understanding how hospitalists' approach compares to cardiologists and what factors are influential in shaping provider decisions to refer to PC may help improve PC delivery to hospitalised patients with advanced HF. Previous studies have evaluated barriers to PC referral in patients with HF. These barriers include: misconstruing $\mathrm{PC}$ with terminal care, such as hospice; lack of clarity around the appropriate timing of introducing PC due to unclear prognosis and desire to continue lifeprolonging interventions; barriers to interprofessional relationships and communication; perceptions that longitudinal providers may better serve patients in making PC referral; and a lack of provider knowledge of $\mathrm{PC}$ and decision support tools. ${ }^{9-12}$ However, these prior studies were qualitative in nature and primarily focused on outpatient providers or contained only a small sampling of hospitalbased providers.

Given this gap, we performed a vignette-based survey study to evaluate factors that may impact hospitalists' and cardiologists' decisions to refer hospitalised patients with HF to PC. We hypothesised that cardiologists would have greater awareness of guidelines compared with hospitalists, but that both would be highly influenced by subjective factors in their decisions to refer to PC.

\section{METHODS}

\section{Study participants and setting}

We recruited hospitalists and cardiologists via three consecutive electronic mail requests to their respective division listservs between January 2019 and May 2019 at three institutions in Michigan (Michigan Medicine, which includes the University of Michigan Medical Centre and Ann Arbor Veterans Affairs Hospital; Henry Ford Health System; and Beaumont Health). We chose these sites because they were all large, multi-site, teaching health systems in which patients with HF have access to robust inpatient subspecialty PC services. All of these systems (with the exception of Beaumont Health) also provided access to outpatient PC services for patients with HF. In addition, we had close contact with leaders at these sites to facilitate survey distribution. To diversify our sample, hospitalists from around the state were also recruited from the Michigan's Society of Hospital Medicine (SHM) Chapter via three consecutive emails to the Chapter listserv. The SHM's Michigan Chapter is a state-wide professional organisation that includes hospitalists from a variety of settings, including community and academic settings. We similarly attempted to recruit cardiologists from varied practice settings using state-wide professional society networks, but 'no solicitation' rules prohibited this. Hence, the cardiologist cohort was restricted to the three academic institutions listed. A $\$ 20$ gift card was provided to participants as a token of appreciation.
This study was deemed exempt by the institutional review boards at all three institutions.

\section{Survey design and data collection}

An electronic, randomised, vignette-based survey was developed for this study (see online supplemental appendix 1) based on a review of the literature related to barriers to PC referral ${ }^{2} 91112$ and discussion with HF and PC content experts. The survey was tested with four hospitalists and three cardiologists with experience in multiple care settings and revised based on results from cognitive interviewing. This was designed as an exploratory study; hence, no sample size calculation was performed.

All participants were presented with a standard vignette of a hospitalised patient with an acute HF exacerbation complicated by acute kidney injury and history of multiple prior hospitalisations, refractoriness to highdose diuretics, and having considered but turned down a left ventricular assist device as an outpatient. We asked participants to report likelihood of referring the patient to PC (scale of $0 \%-100 \%$ ) after the initial stem and again following three successive randomised vignettes containing the following additional details: (a) the presence versus the absence of continuity with an outpatient cardiologist; (b) the presence versus the absence of documented advance care planning; and (c) patient voicing acceptance of their illness versus wanting everything done. Given that the participants could be randomised to 1 of 2 possible vignette modifiers in each category, a total of 8 different permutations were possible for the survey. Figure 1 provides a visual representation of the vignette randomisation.

Participants were also asked their reasons for not referring the patient to $\mathrm{PC}$ after the initial stem, and their impressions and practice related to the percentage of hospitalised patients with HF that they (a) encountered with PC needs; (b) routinely referred to hospice; (c) deferred PC delivery to other providers; and (d) provided PC themselves (without specialty PC involvement). The data on participant age, gender, race, ethnicity, rank, time since training, practice type (ie, academic, community, etc), board certification and formal or informal education in PC, access to subspecialty PC, and awareness of guidelines related to $\mathrm{PC}$ delivery to patients with $\mathrm{HF}$ were also collected. We also asked respondents for their comfort level in determining which patients with $\mathrm{HF}$ would benefit from PC.

\section{Statistical analysis}

Characteristics for hospitalists and cardiologists were compared using $\chi^{2}$ and Fisher's exact tests, as appropriate. Generalised linear models adjusted for age (analysed as a continuous variable), rank, practice type and response to the previous question and predictive margins were used to evaluate the impact of each randomised modifier on likelihood of PC referral. Akaike information criterion and Bayesian information criterion were used to determine which covariates to include in the final model based on 


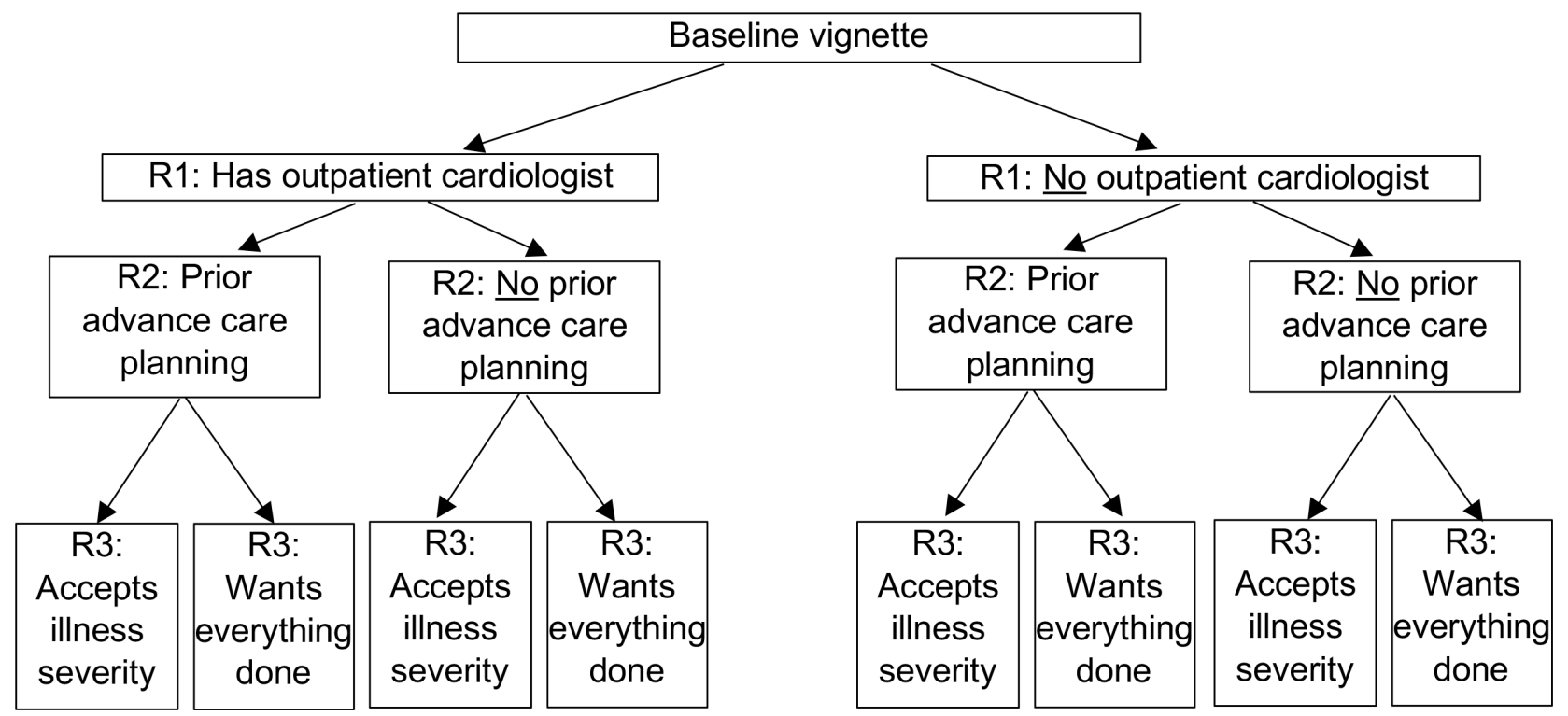

Figure 1 Flowsheet of vignette randomisation. R, randomisation.

best fit. An interaction term was used to evaluate whether provider type (cardiologist vs hospitalist) resulted in different outcomes. Missing data were dropped from the analyses. All analyses were conducted using Stata V.15 (College Station, Texas, USA). A two-tailed $\mathrm{p}$ value of $<0.05$ was considered statistically significant.

\section{Patient and public involvement}

Given this was a provider survey, patients and the public were not included in the conceptualisation or design of this project.

\section{RESULTS}

The overall study response rate was $31.3 \%(n=209 / 667$; $\mathrm{n}=145$ hospitalists and 64 cardiologists, respectively). In some cases, participants chose not to respond to individual questions, so the total $\mathrm{N}$ is reported separately for each question. Characteristics of responding hospitalists and cardiologists are described in table 1. The majority of hospitalists and cardiologists indicated that they were attending physicians; most were employed at an academic medical centre. The majority had access to subspecialty PC in their respective health systems, and approximately half of all providers had formal PC education (either as a trainee or through PC coursework or continued medical education) (table 1).

The mean likelihood of referring the HF patient described in the initial vignette (a patient with acute kidney injury, repeated hospitalisations and worsening diuretic resistance) was similar for hospitalists and cardiologists $(59.2 \%$ vs $58.5 \%, \mathrm{p}=0.56)$. The most common reason for not referring the patient to $\mathrm{PC}$ for cardiologists was that 'the patient's outpatient cardiologist is better suited to make this determination', whereas for hospitalists it was, 'the patient is not imminently dying' (table 2).

In unadjusted generalised linear models, predictive margins demonstrated that providers were statistically significantly more likely to refer the vignette patient to inpatient PC if he (a) did not have a longitudinal relationship with an outpatient cardiologist (unadjusted mean difference: $6.1 \%$ higher compared with a patient with an outpatient cardiologist $(\mathrm{p}=0.006,95 \%$ CI $1.7 \%$ to $10.5 \%)$ ); (b) had evidence of advance care planning documentation in the chart (unadjusted mean difference: $8.7 \%$ higher compared with a patient without evidence of prior advance care planning documentation $(\mathrm{p}<0.001$, $95 \%$ CI $3.4 \%$ to $13.5 \%)$ ); and (c) was accepting of his serious illness (mean difference: $29.0 \%$ higher compared with a patient who voiced that they wanted everything done $(\mathrm{p}<0.001,95 \%$ CI $24.2 \%$ to $33.8 \%))$.

In adjusted generalised linear models, no interactions between provider specialty and responses were observed. Hence, the interaction term was dropped from the final analysis. Predictive margins from generalised linear models adjusted for provider age, rank, practice type and response to the prior vignette demonstrated that providers were statistically significantly more likely to refer the vignette patient to inpatient $\mathrm{PC}$ if he (a) did not have a longitudinal relationship with an outpatient cardiologist (adjusted mean difference: $6.3 \%$ higher compared with a patient with an outpatient cardiologist $(\mathrm{p}=0.006$, $95 \%$ CI $1.8 \%$ to 10.8 )); (b) had evidence of advance care planning documentation in the chart (mean difference: 9.7\% higher compared with a patient with no evidence of prior advance care planning $(\mathrm{p}<0.001$, 95\% CI $4.4 \%$ to $15.0 \%)$ ); and (c) was accepting of his serious illness (mean difference: $29.6 \%$ higher compared with a patient who voiced that they wanted everything done $(\mathrm{p}<0.001$, $95 \%$ CI $24.8 \%$ to $34.4 \%$ )). Adjusted margins' plots show the influence of each vignette modifier on provider likelihood to refer the patient to inpatient PC based on their response to the previous vignette (figures 2-4).

Most hospitalists and cardiologists responded that they were unaware of PG guidelines for patients with $\mathrm{HF}$ 
Table 1 Hospitalist's and cardiologist's characteristics

\begin{tabular}{|c|c|c|c|c|c|}
\hline \multirow[b]{2}{*}{ Characteristics } & \multicolumn{2}{|l|}{ Hospitalists } & \multicolumn{2}{|l|}{ Cardiologists } & \multirow[b]{2}{*}{$P$ value } \\
\hline & Total responses & $\mathbf{N}(\%)$ & Total responses & N (\%) & \\
\hline Age, mean years $\pm S D$ & 132 & $39.0 \pm 8.98$ & 61 & $42.6 \pm 11.4$ & 0.019 \\
\hline Female & 134 & $72(53.73)$ & 63 & $25(39.7)$ & 0.066 \\
\hline \multicolumn{6}{|l|}{ Ethnicity } \\
\hline Hispanic & 134 & $3(2.2)$ & 63 & $0(0)$ & 0.553 \\
\hline \multicolumn{6}{|l|}{ Race } \\
\hline White & 134 & $91(67.9)$ & 62 & $42(67.7)$ & 0.486 \\
\hline Asian & & $30(22.4)$ & & $16(25.8)$ & \\
\hline American Indian or Alaska Native & & $1(0.8)$ & & $0(0)$ & \\
\hline Black or African American & & $0(0)$ & & $1(1.6)$ & \\
\hline Other & & $12(9.0)$ & & $3(4.8)$ & \\
\hline \multicolumn{6}{|l|}{ Rank } \\
\hline Fellow & 134 & $1(0.8)$ & 62 & $23(37.1)$ & $<0.001$ \\
\hline Attending & & $98(73.1)$ & & $37(59.7)$ & \\
\hline Advanced Practitioner (NP, PA) & & $19(14.2)$ & & $2(3.2)$ & \\
\hline Other & & $16(11.9)$ & & $0(0)$ & \\
\hline Time since training, mean years $\pm S D$ & 129 & $8.1 \pm 8.0$ & 59 & $9.0 \pm 11.3$ & 0.534 \\
\hline Practice setting & & & & & 0.001 \\
\hline Academic & 134 & $81(60.5)$ & 63 & $52(82.5)$ & \\
\hline VA & & $5(3.7)$ & & $4(6.4)$ & \\
\hline Community & & $45(33.6)$ & & $7(11.1)$ & \\
\hline Other & & $3(2.2)$ & & $0(0)$ & \\
\hline Board certified in PC & 134 & $7(5.2)$ & 62 & $1(1.6)$ & 0.439 \\
\hline Formal education in PC & 133 & $72(54.1)$ & 63 & $33(52.4)$ & 0.818 \\
\hline Additional coursework in PC & 133 & $39(29.3)$ & 63 & $9(14.3)$ & 0.022 \\
\hline \multicolumn{6}{|l|}{ Access to subspecialty PC } \\
\hline Yes, inpatient only & 134 & $31(23.1)$ & 63 & $9(14.3)$ & 0.272 \\
\hline Yes, inpatient and outpatient & & $93(69.4)$ & & $51(81.0)$ & \\
\hline Yes, outpatient only & & $4(3.0)$ & & $0(0)$ & \\
\hline No, neither inpatient nor outpatient & & $2(1.5)$ & & $2(3.2)$ & \\
\hline Not sure & & $4(3.0)$ & & $1(1.6)$ & \\
\hline \multicolumn{6}{|c|}{ Aware of guidelines for PC in patients with HF } \\
\hline Yes, they are helpful & 145 & $38(26.2)$ & 64 & $14(21.9)$ & 0.712 \\
\hline Yes, but they are not helpful & & $5(3.5)$ & & $3(4.7)$ & \\
\hline No, I do not know of any guidelines & & $102(70.3)$ & & $47(74.3)$ & \\
\hline \multicolumn{6}{|c|}{ Comfort level with identifying patients with HF in need of PC } \\
\hline Very comfortable & 145 & $34(23.5)$ & 64 & $23(35.9)$ & 0.175 \\
\hline Somewhat comfortable & & $67(46.2)$ & & $31(48.4)$ & \\
\hline Neutral & & $26(17.9)$ & & $6(9.4)$ & \\
\hline Somewhat uncomfortable & & $16(11.0)$ & & $4(6.3)$ & \\
\hline Very uncomfortable & & $2(1.4)$ & & $0(0)$ & \\
\hline
\end{tabular}

HF, heart failure; NP, nurse practitioner; PA, physician's assistant; PC, palliative care; VA, veteran's affairs.

(74.3\% vs $70.3 \%, \mathrm{p}=0.71$ ) (table 1 ). No differences were noted when hospitalists and cardiologists were asked what percentage of their hospitalised patients with HF had PC needs $(51.6 \%$ vs $50.2 \%, \mathrm{p}=0.71)$ and what percentage they referred to hospice $(34.8 \%$ vs $36.0 \%, \mathrm{p}=0.76)$. Similarly, they reported similar percentages of patients in whom 
Table 2 Reasons for not referring HF patient to PC

\section{A: hospitalist reasons $(n=258)^{*}$}

1. The patient is not imminently dying

N $\%$

$47 \quad 18.2$

2. The patient's outpatient cardiologist is better suited to make this determination

3. I would provide palliative interventions myself

$41 \quad 15.9$

4. The patient does not have clear PC needs at this time

$38 \quad 14.7$

$32 \quad 12.4$

5. I do not want Mr Jones to feel like I have given up on him

$20 \quad 7.8$

6. The patient's primary care doctor is better suited to make this determination

$19 \quad 7.4$

7. I would first explore the patient's goals/preferences

$15 \quad 5.8$

8. I do not want Mr Jones's family to feel like I have given up on him

$15 \quad 5.8$

9. I would want cardiology to weigh in first

$8 \quad 3.1$

10. We do not have an inpatient PC team

$7 \quad 2.7$

11. We have an inpatient PC team, but I have not had good experiences referring patients to them

12. Other

13. The patient would benefit from outpatient rather than inpatient PC

$7 \quad 2.7$

$4 \quad 1.6$

$3 \quad 1.1$

14. I do not know how best to connect the patient with palliative services care

$2 \quad 0.8$

Total

\section{B: cardiologist reasons $(n=111)^{*}$}

$258 \quad 100.0$

1. The patient's outpatient cardiologist is better suited to make this determination

N \%

2. I do not want Mr Jones to feel like I have given up on him

$21 \quad 18.9$

$17 \quad 15.3$

3. The patient is not imminently dying

$16 \quad 14.4$

4. I do not want Mr Jones's family to feel like I have given up on him

$14 \quad 12.6$

5. I would provide palliative interventions myself

$10 \quad 9.0$

6. The patient does not have clear PC needs at this time

7. I would first explore the patient's goals/preferences

$8 \quad 7.2$

$8 \quad 7.2$

8. The patient's primary care doctor is better suited to make this determination

54.5

9. I would first try medical interventions

$4 \quad 3.6$

10. We have an inpatient PC team, but I have not had good experiences referring patients to them

$3 \quad 2.7$

11. Other

12. We do not have an inpatient PC team

10.9

13. I do not know how best to connect the patient with palliative services care

Total

10.9

$111 \quad 100.0$

${ }^{*}$ Respondents could select more than one choice; hence, $\mathrm{N}$ is larger than the number of sample participants.

$\mathrm{HF}$, heart failure; PC, palliative care.

they delivered PC themselves without specialty PC (35.9\% vs $40.8 \%, \mathrm{p}=0.34$ ). However, compared with hospitalists, cardiologists were more likely to report that they deferred PC delivery to other providers $(53.6 \%$ vs $43.4 \%, \mathrm{p}=0.03)$ (table 3).

\section{DISCUSSION}

Our study demonstrates that regardless of specialty, patient and provider factors are highly influential in provider decisions to refer hospitalised patients with HF to PC. We deliberately created a clinical vignette with several objective, high-risk features for mortality, including renal dysfunction, recurrent hospitalisations and disease progression despite optimal management.
However, these clinical measures were less influential in PC referral. Respondents in our study were more likely to refer patients who did not have an outpatient cardiologist, had advance care directives or were more accepting of the severity of their illness. These latter two findings are concerning in that patients without prior documented advanced care planning conversations and those who are struggling to accept their illness stand to benefit most from PC. ${ }^{413}$ Generalist or specialty PC interventions for such patients could include goals of care conversations and evaluation of prognostic awareness, as well as psychosocial and spiritual assessment to better understand the reasons behind why they have particular preferences around their disease management. ${ }^{2}$ While it is not clear 

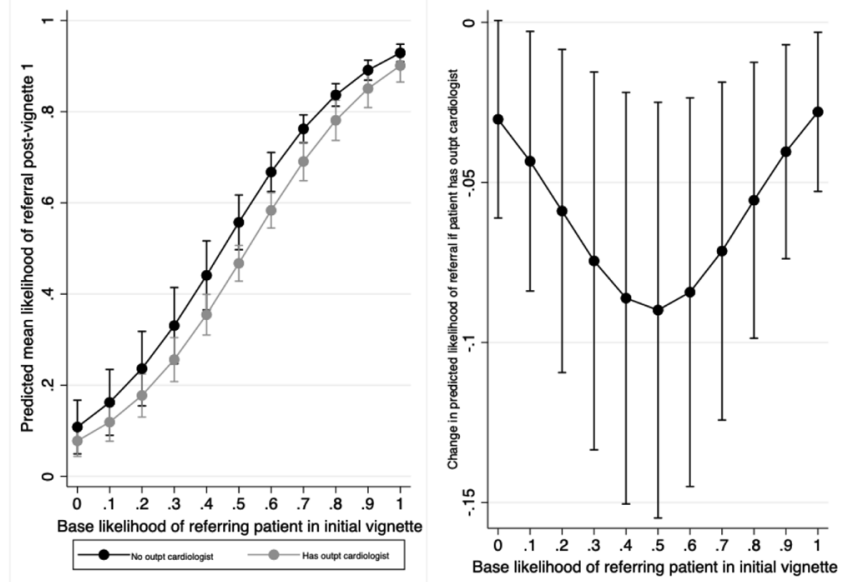

Figure 2 Differences in predictive margins for likelihood of referring patient to palliative care $(P C)$ based on the presence or the absence of an outpatient cardiologist. The panel on the left plots the base likelihood (\%) of referring the patient with heart failure in the initial vignette to $P C(X$-axis) against the predicted mean likelihood (\%) that they would refer the patient after learning that he either (grey) has an outpatient cardiologist or (black) does not have an outpatient cardiologist (Y-axis). The error bars represent 95\% Cls.

Overall, participants were less likely to refer a patient to $P C$ if the patient had an outpatient cardiologist. The panel on the right demonstrates the change in the predicted likelihood of referral if the patient has an outpatient cardiologist ( $Y$-axis) based on the likelihood of referring the patient in the initial vignette (X-axis).

why these contradictory referral patterns emerged in our study, they highlight a missed opportunity for PC referral in this population. Further evaluation with qualitative or ethnographic studies is warranted to better understand why these contradictory findings arose.

Prior studies have shown that several other provider and patient factors are influential in PC referral decisions. First, prognostic uncertainty has frequently been cited as a barrier to timely PC and hospice referral. ${ }^{14}$ Second, low knowledge of the benefits of PC in advanced patients with HF throughout the disease continuum, and/or conflation of PC with hospice services often leads to delays in referral until patients are more imminently near death. ${ }^{914}$ Our findings support these data and also highlight an important need for PC education among providers. Just half of the providers in our study had formal PC training and most had limited knowledge of guidelines around the timing and appropriateness of PC referral in patients with HF. Finally, some HF providers feel that honouring prior patient-provider relationships among outpatient cardiologists and primary care providers is important in determining who is best suited to initiate PC referral. ${ }^{14}$ This latter point may explain why cardiologists were more likely to defer decisions around PC referral to other providers in our study. Collectively, these findings suggest that decisions around PC referral
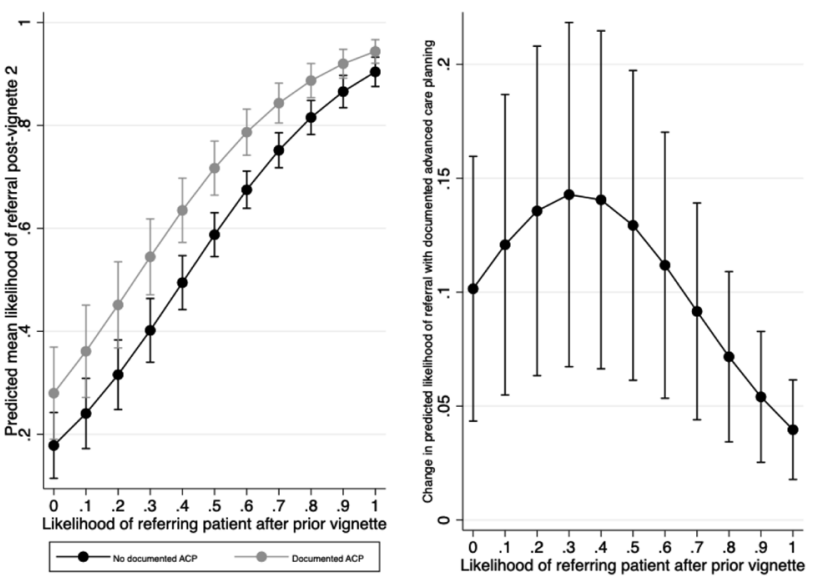

Figure 3 Differences in predictive margins for likelihood of referring patient to palliative care $(\mathrm{PC})$ based on the presence or the absence of documented advanced care planning. The panel on the left plots the base likelihood (\%) of referring the patient with heart failure in the previous vignette (the presence or the absence of an outpatient cardiologist) (Xaxis) against the predicted mean likelihood (\%) that they would refer the patient after learning that he either (grey) has documented advance care planning (ACP) or (black) no documented ACP (Y-axis). The error bars represent 95\% Cls. Overall, participants were more likely to refer a patient to PC if the patient had prior documented ACP. The panel on the right demonstrates the change in the predicted likelihood of referral if the patient has prior documented ACP (Y-axis)
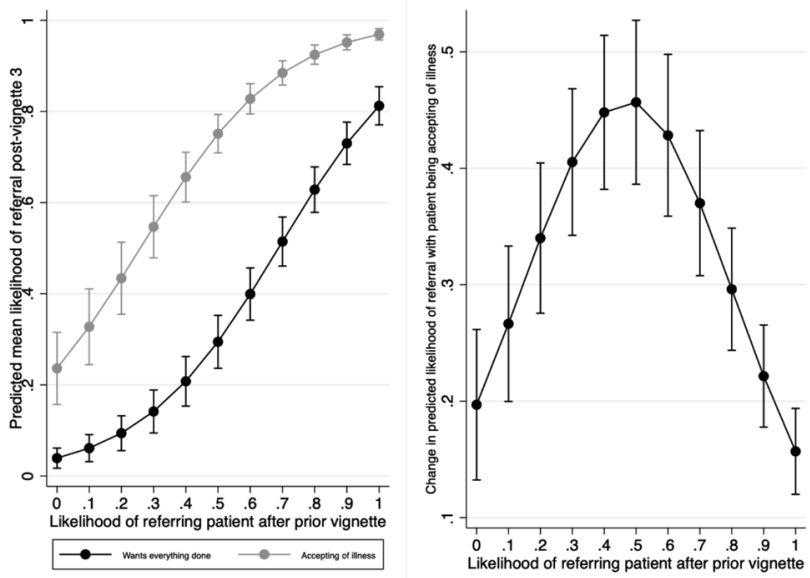

Figure 4 Differences in predictive margins for likelihood of referring patient to palliative care $(\mathrm{PC})$ based on patient being accepting of illness vs wanting everything done. The panel on the left plots the base likelihood (\%) of referring the patient with heart failure in the previous vignette (the presence or the absence of advance care planning documentation) to PC (X-axis) against the predicted mean likelihood (\%) that they would refer the patient after learning that he either (grey) is accepting of his illness or (black) wants everything done for his illness (Y-axis). The error bars represent 95\% Cls. Overall, participants were more likely to refer a patient to PC if the patient was accepting of his illness. The panel on the right demonstrates the change in the predicted likelihood of referral if the patient was accepting of his illness ( $Y$-axis) based on the likelihood of referring the patient in the previous vignette (X-axis). 
Table 3 General practice patterns around PC for hospitalised patients with HF among hospitalists and cardiologists

\begin{tabular}{|c|c|c|c|c|c|c|c|}
\hline & \multicolumn{3}{|c|}{ Hospitalists $(\mathrm{N}=145)$} & \multicolumn{3}{|c|}{ Cardiologists ( $\mathrm{N}=64)$} & \multirow[b]{2}{*}{$P$ value } \\
\hline & $\begin{array}{l}\text { Total } \\
\text { responses }\end{array}$ & $\begin{array}{l}\text { Mean \% } \\
\text { reported }\end{array}$ & SD & $\begin{array}{l}\text { Total } \\
\text { responses }\end{array}$ & $\begin{array}{l}\text { Mean \% } \\
\text { reported }\end{array}$ & SD & \\
\hline $\begin{array}{l}\text { Percentage of hospitalised patients with HF } \\
\text { that you refer to hospice }\end{array}$ & 137 & 36.0 & 28.1 & 62 & 34.8 & 26.6 & 0.761 \\
\hline $\begin{array}{l}\text { Percentage of hospitalised patients with HF in } \\
\text { which you defer PC to another provider }\end{array}$ & 135 & 43.4 & 29.8 & 58 & 53.6 & 32.1 & 0.034 \\
\hline
\end{tabular}

$\mathrm{HF}$, heart failure; $\mathrm{PC}$, palliative care.;

in HF may be underinformed and variable, translating into delayed or absent PC referral in end-stage patients with HF.

There is little denying that many patients with advanced HF experience poorly coordinated, fragmented care at the end of life, frequently moving in and out of acute care settings with little time to engage with longitudinal providers. As such, hospitalisations become an important 'touch point' during which to elicit patient goals and values around their care and engage PC. ${ }^{15}$ At the provider level, raising awareness of guidelines and the role of PC in alleviating suffering is an important first step among hospitalists and cardiologists alike. ${ }^{2}$ Additionally, interventions specifically aiming to enhance interprofessional and interprovider communication could help clarify roles and expectations around when and how to introduce PC to patients who traverse many care settings and providers. ${ }^{16}$ For example, given the influence of advance care planning documentation on provider decisions in our study, documenting and communicating advance care planning can ensure that patient preferences are communicated across care settings. ${ }^{13}$ Additionally, other system-based interventions such as decision support tools based on prediction models ${ }^{17}$ may help identify patients who would benefit from PC, removing subjective assessments that may delay PC referral. Tools such as these have been developed to assist in decision-making for end-stage patients with HF who are being evaluated for destination therapies ${ }^{18}$ and could similarly be adapted for use for inpatients with HF in need of PC.

\section{Limitations}

Our study has limitations. First, the response rate was low, though this is comparable to other previously published multi-institutional surveys of hospitalists evaluating practice patterns and attitudes. ${ }^{19}$ Second, as most respondents came from academic settings, our findings may not be generalisable to community settings. Third, while most participants in our study had access to specialty PC services, lack of access to $\mathrm{PC}$ is an important barrier to timely PC referral for patients with HF not addressed by our study.

\section{CONCLUSIONS}

Many patient and provider factors are highly influential in provider decisions around referring hospitalised patients with HF to PC, perhaps more than clinical measures alone. Better understanding of these factors are needed to inform interventions that improve access to PC for this vulnerable group.

\section{Author affiliations}

${ }^{1}$ Department of Medicine, Division of Palliative Medicine, University of California, San Francisco, California, USA

${ }^{2}$ Institute for Health Metrics and Evaluation, University of Washington, Seattle, Washington, USA

${ }^{3}$ Department of Internal Medicine, Division of Cardiovascular Medicine, University of Michigan, Ann Arbor, Michigan, USA

${ }^{4}$ Veterans Affairs Ann Arbor Healthcare System, Ann Arbor, Michigan, USA ${ }^{5}$ Department of Internal Medicine, Division of Hospital Medicine, University of Michigan, Ann Arbor, Michigan, USA

${ }^{6}$ Section of Cardiovascular Medicine, Yale School of Medicine, New Haven, Connecticut, USA

${ }^{7}$ Department of Medicine, Division of Cardiology, Henry Ford Health System, Detroit, Michigan, USA

Twitter Nauzley Christy Abedini @NauzleyAbedini and Michael Beasley @ MHBeasleyMD

Acknowledgements The authors would like to thank Suzanne Winter for project management and contributions to survey design and dissemination, as well as Trevor McCarty for his contributions to survey design.

Contributors All authors meet the ICMJE criteria for authorship. Conceptualisation or intervention, and study design: NCA, SLH and VC. Data collection: NCA, SLH, DB, $\mathrm{MB}$ and JC. Data analysis and interpretation, and writing, reviewing and editing: NCA, GG, SLH, DB, MB, JC and VC. Writing original draft: NCA.

Funding Dr Abedini's work was supported by the University of Michigan's National Clinician Scholars Program at the Institute for Health Policy and Innovation and Division of Hospital Medicine. Dr Chopra is supported by grant funding from the Agency for Healthcare Research and Quality.

Competing interests None declared.

Patient consent for publication Not required.

Provenance and peer review Not commissioned; externally peer reviewed.

Data availability statement Data are available upon reasonable request. Deidentified raw participant data and statistical analysis are available upon request.

Supplemental material This content has been supplied by the author(s). It has not been vetted by BMJ Publishing Group Limited (BMJ) and may not have been peer-reviewed. Any opinions or recommendations discussed are solely those of the author(s) and are not endorsed by BMJ. BMJ disclaims all liability and responsibility arising from any reliance placed on the content. Where the content 
includes any translated material, BMJ does not warrant the accuracy and reliability of the translations (including but not limited to local regulations, clinical guidelines, terminology, drug names and drug dosages), and is not responsible for any error and/or omissions arising from translation and adaptation or otherwise.

Open access This is an open access article distributed in accordance with the Creative Commons Attribution Non Commercial (CC BY-NC 4.0) license, which permits others to distribute, remix, adapt, build upon this work non-commercially, and license their derivative works on different terms, provided the original work is properly cited, appropriate credit is given, any changes made indicated, and the use is non-commercial. See: http://creativecommons.org/licenses/by-nc/4.0/.

\section{ORCID iD}

Nauzley Christy Abedini http://orcid.org/0000-0003-4949-1958

\section{REFERENCES}

1 Rogers JG, Patel CB, Mentz RJ, et al. Palliative care in heart failure: the PAL-HF randomized, controlled clinical trial. J Am Coll Cardiol 2017;70:331-41.

2 Psotka MA, McKee KY, Liu AY, et al. Palliative care in heart failure: what triggers specialist consultation? Prog Cardiovasc Dis 2017;60:215-25.

3 Fang JC, Ewald GA, Allen LA, et al. Advanced (stage D) heart failure: a statement from the heart failure Society of America guidelines Committee. J Card Fail 2015;21:519-34.

4 Allen LA, Stevenson LW, Grady KL, et al. Decision making in advanced heart failure: a scientific statement from the American heart association. Circulation 2012;125:1928-52.

5 Mandawat A, Heidenreich PA, Mandawat A, et al. Trends in palliative care use in veterans with severe heart failure using a large national cohort. JAMA Cardiol 2016;1:617-9.

6 Unroe KT, Greiner MA, Hernandez AF, et al. Resource use in the last 6 months of life among medicare beneficiaries with heart failure, 2000-2007. Arch Intern Med 2011;171:196-203.

7 Kociol RD, Hammill BG, Fonarow GC, et al. Associations between use of the hospitalist model and quality of care and outcomes of older patients hospitalized for heart failure. JACC Heart Fail 2013;1:445-53.

8 Ko DT, Tu JV, Masoudi FA, et al. Quality of care and outcomes of older patients with heart failure hospitalized in the United States and Canada. Arch Intern Med 2005;165:2486-92.

9 Kavalieratos D, Mitchell EM, Carey TS, et al. "Not the 'grim reaper service'": an assessment of provider knowledge, attitudes, and perceptions regarding palliative care referral barriers in heart failure. $J$ Am Heart Assoc 2014;3:e000544.

10 Ziehm J, Farin E, Seibel K, et al. Health care professionals' attitudes regarding palliative care for patients with chronic heart failure: an interview study. BMC Palliat Care 2016;15:76.

11 Browne S, Macdonald S, May CR, et al. Patient, carer and professional perspectives on barriers and facilitators to quality care in advanced heart failure. PLoS One 2014;9:e93288.

12 Singh GK, Davidson PM, Macdonald PS, et al. The perspectives of health care professionals on providing end of life care and palliative care for patients with chronic heart failure: an integrative review. Heart Lung Circ 2019;28:539-52.

13 Warraich HJ, Meier DE. Serious-IIlness Care 2.0 - Meeting the Needs of Patients with Heart Failure. N Engl J Med 2019;380:2492-4.

14 Kavalieratos D, Gelfman LP, Tycon LE, et al. Palliative care in heart failure: rationale, evidence, and future priorities. J Am Coll Cardiol 2017;70:1919-30.

15 Slavin SD, Warraich $\mathrm{HJ}$. The right time for palliative care in heart failure: a review of critical moments for palliative care intervention. Rev Esp Cardiol 2020;73:78-83.

16 Wiskar K, Toma M, Rush B. Palliative care in heart failure. Trends Cardiovasc Med 2018;28:445-50.

17 Lagu T, Pekow PS, Shieh M-S, et al. Validation and comparison of seven mortality prediction models for hospitalized patients with acute decompensated heart failure. Circ Heart Fail 2016;9.

18 Thompson JS, Matlock DD, Mcllvennan CK, et al. Development of a decision aid for patients with advanced heart failure considering a destination therapy left ventricular assist device. JACC Heart Fail 2015;3:965-76

19 Chopra V, Kuhn L, Coffey CE, et al. Hospitalist experiences, practice, opinions, and knowledge regarding peripherally inserted central catheters: a Michigan survey. J Hosp Med 2013;8:309-14. 